\title{
EQUILÍBRIO LÍQUIDO-LÍQUIDO DO SISTEMA PSEUDOTERNÁRIO CONTENDO ÓLEO DE SOJA + BIODIESEL $+($ ETANOL + ÁGUA)
}

\author{
J. L. A. DAGOSTIN ${ }^{1}$, L. R. S. KANDA ${ }^{1}$, A. M. ESCORSIM ${ }^{1}$, L. P. RAMOS ${ }^{2}$, M. R. MAFRA ${ }^{1}$ e \\ M. L. CORAZZA ${ }^{1}$ \\ ${ }^{1}$ Universidade Federal do Paraná, Departamento de Engenharia Química \\ ${ }^{2}$ Universidade Federal do Paraná, Departamento Química \\ E-mail para contato: corazza@ufpr.br
}

\begin{abstract}
RESUMO - A literatura atual dispõe de diversos estudos do equilíbrio termodinâmico das etapas de purificação de biodiesel. No entanto, dados de solubilidade do meio reacional para sua produção são escassos. Este estudo visou compreender a solubilidade de misturas envolvendo os sistemas óleo de soja + biodiesel + (etanol + água) a 25, 40 e $60{ }^{\circ} \mathrm{C}$. Biodiesel foi produzido a partir de óleo de soja por transesterificação alcalina $(\mathrm{NaOH})$ com etanol. A concentração do biodiesel $(97,63 \%)$ foi verificada por cromatografia de permeação em gel. As curvas de solubilidade foram obtidas por titulometria. As linhas de amarração foram obtidas por gravimetria e refratometria. A concentração de água foi medida por Karl Fischer. Para ambos os sistemas o aumento da temperatura influenciou positivamente a solubilidade da mistura. $\mathrm{O}$ aumento no teor de água diminuiu de forma significativa a solubilidade entre os componentes dos sistemas.
\end{abstract}

\section{INTRODUÇÃO}

Biodiesel é uma mistura de ésteres monoalquílicos que podem ser obtidos por diferentes tecnologias a partir de óleos, gorduras ou ácidos graxos de fontes animais ou vegetais. Um dos métodos mais utilizados para sua obtenção envolve a alcoólise (transesterificação) de óleos catalisada por um álcali. Neste processo, normalmente é feito o uso de álcoois de cadeia curta, como metanol ou etanol. Dentro deste contexto, o Brasil se destaca como o principal produtor de cana-de-açúcar. Além disso, é o segundo maior produtor de soja, importante fonte de óleo para os mais diversos fins, entre eles a produção de biodiesel. Isso significa que existe uma grande oportunidade no país para a pesquisa e produção de biodiesel a partir destas matérias-primas (Mazutti et al., 2013).

Um dos principais obstáculos da transesterificação etílica de óleos e gorduras ocorre devido à capacidade deste álcool formar misturas azeotrópicas com água. A presença de água no reator promove a formação de produtos indesejáveis, como os sabões. Concomitantemente à formação destes produtos está o consumo de catalisador e a consequente diminuição do rendimento em ésteres. Em certo grau, a presença de sabões pode comprometer todo o meio reacional pela formação de uma emulsão estável (Atadashi et al., 2012).

Independentemente do processo empregado, conhecer o diagrama de fases para uma mistura 
multicomponente é a chave central para a simulação e a otimização de um processo adequado e confiável para a produção de biodiesel. Assim, este trabalho teve por objetivo a obtenção de dados de equilíbrio líquido-líquido de sistemas envolvendo óleo de soja + biodiesel + (etanol + água) a temperaturas de $298,15 \mathrm{~K}$ a $333,15 \mathrm{~K}$.

\section{MATERIAL E MÉTODOS}

\subsection{Materiais}

Produção do biodiesel: Para produzir o biodiesel, utilizou-se óleo de soja neutro (IMCOPA, Curitiba, Brasil), etanol anidro (Panreac), hidróxido de sódio (Merck), Perlimax ${ }^{\circledR}$ P-175 e sulfato de sódio anidro (Nuclear).

Ensaios de solubilidade: Utilizou-se óleo de soja refinado (Liza), etanol anidro e etanol 96\% vol (Panreac).

Determinação da composição dos sistemas: Fez-se o uso de acetato de etila (F.Maia), reagente de Karl Fisher (Panreac) e metanol seco (Panreac).

Todos os reagentes e matérias-primas foram utilizados como recebidos.

\subsection{Métodos}

Produção de biodiesel: O biodiesel de óleo de soja foi obtido por transesterificação alcalina. Para isso foi utilizado $0.3 \%$ hidróxido de sódio $(\mathrm{m} / \mathrm{m}$ óleo) e uma razão molar de etanol:óleo igual a 12:1, considerando a massa molar média do óleo igual a $886 \mathrm{~g} \mathrm{~mol}^{-1}$. A reação ocorreu num reator de $2 \mathrm{~L}$ equipado com condensador de refluxo por $1 \mathrm{~h}$ a $343 \mathrm{~K}$. A recuperação do excesso de etanol foi feita em rotaevaporador. A separação das fases éster e glicerol foi realizada por centrifugação a $2500 \mathrm{rpm}$ por $10 \mathrm{~min}$. A fração de ésteres foi lavada com água deionizada a $353,15 \mathrm{~K}$ por 6 vezes. Após a lavagem, Perlimax ${ }^{\circledR} \mathrm{P}-175(2 \% \mathrm{~m} / \mathrm{m}$ em relação à massa de éster $)$ foi adicionado ao éster, que foi mantido sob agitação constante por $30 \mathrm{~min}$. A mistura foi filtrada por duas vezes, sendo utilizado sulfato de sódio anidro $(3 \% \mathrm{~m} / \mathrm{m}$ em relação aos ésteres) na membrana da segunda filtragem para redução do teor de água do biodiesel.

O teor de éster foi verificado por cromatografia de permeação em gel conforme (Schoenfelder, 2003; Darnoko et al., 2000). Foi utilizado um detector Waters ${ }^{\circledR} 2414$ acoplado por duas colunas TSK-Gel ${ }^{\circledR}$ (Stuttgart, Alemanha) modelos G2000Hxl e G1000Hxl e uma coluna de guarda. A fase móvel foi tetrahidrofurano a uma vazão de $0,8 \mathrm{~mL} \mathrm{~min}^{-1}$ a 313,15 K. A diluição das amostras foi realizada em isopropanol a $5 \mathrm{mg} \mathrm{mL}^{-1}$ e o volume de injeção foi igual a $20 \mu \mathrm{L}$. As curvas de calibração foram realizadas por padronização externa utilizando soluções de oleato de etila, glicerol e mono, di e trioleína como padrões de referência para mono, di e triacilglicerois, respectivamente.

Determinação das curvas de solubilidade e linhas de amarração: Os dados de equilíbrio líquido-líquido (ELL) foram obtidos em células de equilíbrio conforme descrito por (da Silva et al., 2013, Kanda et al., 2013). A temperatura das células foi monitorada por indicador de temperatura Watlow SD31 com sensor PT100 $( \pm 0,1 \mathrm{~K})$ e controlada por banho ultratermostático (Nova Ética 521/D). Os dados de ELL foram determinados a 298,15 K, 313,15 K e 333,15 K. As 
linhas de amarração foram obtidas após agitação vigorosa (100 min) de composições conhecidas do sistema, seguidas de descanso por $16 \mathrm{~h}$. A temperatura das células foi mantida até o momento de coleta das fases.

A composição das fases foi determinada por dois métodos analíticos. Primeiro, a fração volátil foi determinada gravimetricamente pela evaporação das amostras em estufa a vácuo (QUIMIS Q319V6) por duas vezes a 323,15 K e $2 \mathrm{~h}$. Todo o evaporado foi considerado como etanol + água. As frações resultantes de óleo + biodiesel foram medidas em refratômetro Abbe (Biobrix, 2WAJ) e correlacionadas com uma curva de calibração construída a partir de onze concentrações de óleo + biodiesel e cinco diferentes temperaturas $(283.15,298.15,313.3,333.15$ and 348,15 K). A curva de calibração corresponde à Equação 1,

$w_{1}=-82.0284+0.0195 . T+52.4361 . n$

onde $w_{1}$ é a fração mássica do óleo na mistura binária (óleo de soja + biodiesel), $T$ é a temperatura (K) da medida do índice de refração e $n$ é o índice de refração obtido. A equação apresentou um $\mathrm{R}^{2}=0,9982$ e erros $\left(w_{1}=\mathrm{A}+\mathrm{B} . T+\mathrm{C} . n\right)$ iguais a: $\mathrm{A} \pm 0,4760, \mathrm{~B} \pm 0,0001$ e $\mathrm{C} \pm 0,3018 . \mathrm{A}$ diferença entre os valores reais e os preditos foi estimada em menos de 1,2\% (fração mássica).

Determinação do teor de água: O conteúdo de água dos componentes e fases coletadas foi avaliado por titulação de Karl Fischer (Mettler-Toledo modelo V30) pelo método oficial Ca 2e-84 da AOCS (AOCS, 2001). As amostras foram homogeneizadas com acetato de etila para evitar separação de fases e o teor de água foi corrigido considerando o acetato de etila adicionado.

\section{RESULTADOS E DISCUSSÃO}

As curvas de solubilidade e linhas de amarração para os sistemas pseudoternários envolvendo óleo de soja + biodiesel + etanol estão representadas na Figura 1, enquanto a Figura 2 representa os dados obtidos para o sistema óleo de soja + biodiesel + (etanol + água). No sistema contendo etanol hidratado a 298,15 K, considerou-se o sistema como quaternário (óleo de soja + biodiesel + etanol + água), sendo a fração de água obtida por titulação de Karl-Fisher. Já para o mesmo sistema a 313,15 K e 333,15 K (Figuras 2(B) e (C)) considerou-se a mistura como pseudoternária, sendo o binário etanol + água tomado como um pseudocomponente. Fez-se isso uma vez que menores desvios nos dados de solubilidade foram encontrados para maiores temperaturas neste sistema. As misturas de biodiesel em etanol absoluto e etanol $96 \%$ se apresentaram completamente miscíveis nas faixas de temperatura estudadas, enquanto as misturas de óleo de soja ao etanol mostraram ser solúveis em apenas faixas restritas de suas concentrações. Para verificar a confiabilidade dos dados experimentais de ELL para os sistemas estudados, empregou-se a equação de Othmer-Tobias (Equação 2) nas linhas de amarração obtidas (Othmer e Tobias, 1942):

$$
\log \frac{\left(1-w_{1}^{E P}\right)}{w_{1}^{E P}}=a+b \cdot \log \frac{\left(1-w_{3}^{O P}\right)}{w_{3}^{O P}}
$$

sendo, $w_{1}^{E P}$ a fração mássica de óleo na fase etanol, $w_{3}{ }^{O P}$ a fração mássica de etanol na fase óleo, e $a$ e $b$ os coeficientes linear e angular da reta traçada, respectivamente. 


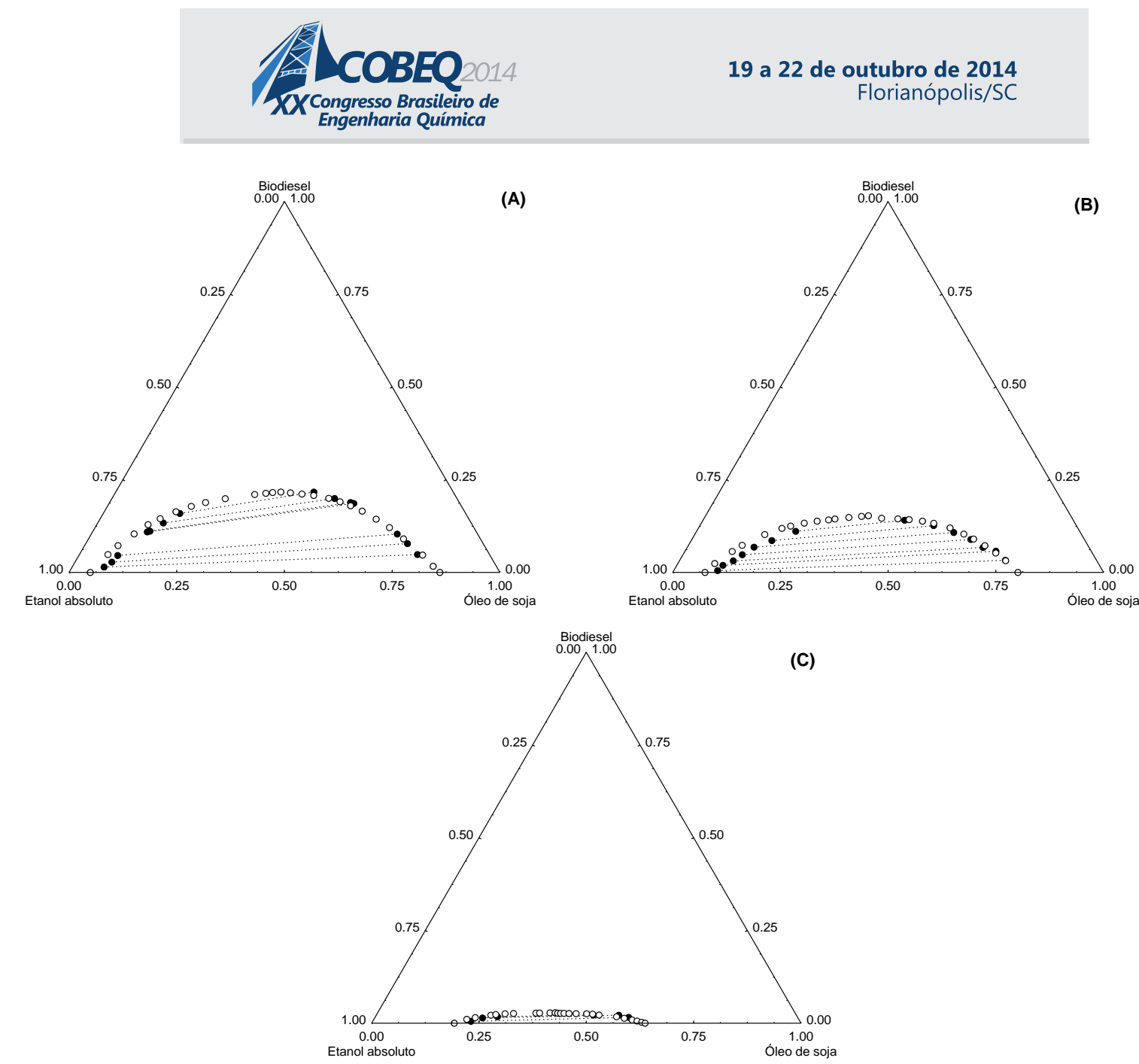

Figura 1 - Diagrama ternário do sistema óleo de soja + biodiesel + etanol absoluto, a (A) 298,15 K, (B) 313,15 K e (C) 333,15 K. Binodais (०) e linhas de amarração experimentais $(\bullet)$. 


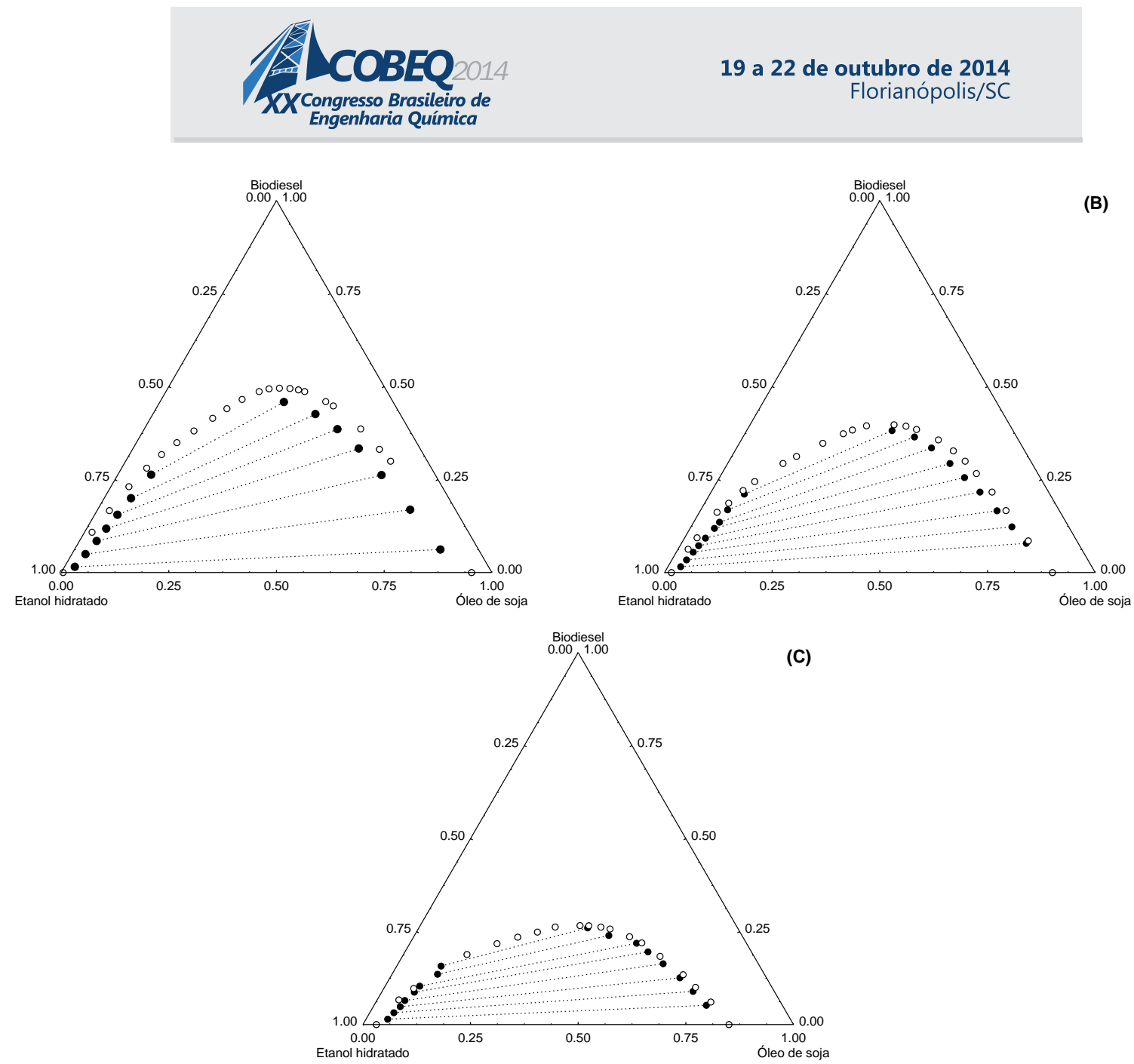

Figura 2 - Diagrama ternário do sistema óleo de soja + biodiesel + (etanol + água), a (A) 298,15 K, (B) 313,15 K e (C) 333,15 K. Binodais (०) e linhas de amarração experimentais $(\bullet)$. 
Na Figura 3 encontram-se os ajustes das linhas de amarração à Equação 5. Os coeficientes de correlação para os conjuntos de dados ajustados apresentaram valor maior que 0,9920 , exceto para o sistema envolvendo etanol absoluto a $333,15 \mathrm{~K}$, onde $\mathrm{R}^{2}=0,9608$.

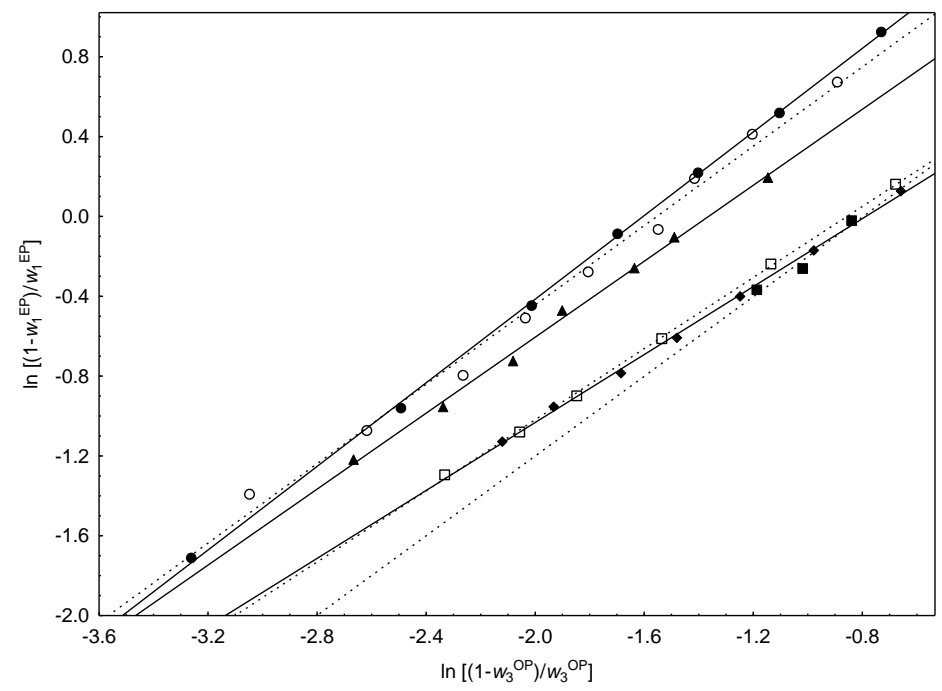

Figura 3 - Ajuste na equação de Othmer-Tobias para os sistemas com etanol absoluto a 298,15(

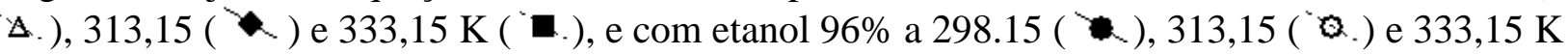
$(\mathbf{\Delta})$.

O uso de etanol hidratado na produção de biodiesel de transesterificação alcalina já é conhecido por formar subprodutos como sabões e afetar negativamente a taxa de reação e rendimento (Atadashi et al., 2012). De acordo com os dados obtidos neste trabalho, também é possível afirmar que o uso de etanol hidratado torna o sistema menos favorável termodinamicamente como solução homogênea, ou seja, provavelmente ocorrerá um menor contato molecular e, consequentemente, uma menor taxa de reação. Experimentalmente, verificouse que o sistema torna-se completamente miscível quando a concentração de biodiesel em etanol absoluto for maior que 21,7, 15,3 e 2,9\% (massa) nas temperaturas de 298,15, 313,15 e 333,15 K, respectivamente. Enquanto isso, uma maior quantidade de biodiesel se fez necessária quando etanol hidratado foi utilizado: 49,6, 39,7 e 26,6\% (massa) de biodiesel para as respectivas temperaturas acima descritas. Isto significa que é possível utilizar uma fração do produto (biodiesel) em sistemas de transesterificação como agente solubilizante. No entanto, como o biodiesel é produto da própria reação, a qual é reversível, deve-se levar em conta que o equilíbrio da reação deverá ser deslocado em favor dos reagentes. Este deslocamento deverá ser maior ou menor, quanto mais ou menos biodiesel for adicionado. Assim, é importante que os parâmetros do processo de reação sejam escolhidos de forma a permitir maior e mais rápida conversão em produtos, aliados ao menor gasto energético. A partir das condições estudadas, podemos inferir que aquela que apresenta melhor resultado é o sistema que utiliza etanol anidro a 333,15 K. Neste sistema, a solubilidade é completa quando no mínimo 2,9\% de biodiesel é adicionado, o que provavelmente não deve deslocar o sentido da reação de forma significativa. Estudos posteriores envolvendo a cinética de produção de biodiesel e formação de subprodutos devem ser realizados para compreender a real influência da adição dos ésteres ao meio de reação. Este procedimento pode ser útil para otimizar a taxa de reação, principalmente em reatores que não possuam uma agitação adequada no sistema. 


\section{CONCLUSÃO}

Neste trabalho, foram apresentados dados de equilíbrio liquido-líquido para sistemas ternários contendo óleo de soja + biodiesel + (etanol + água) a $\mathrm{T}=(278,15,313,15$ e 333,15) $\mathrm{K}$. Em temperaturas superiores, os sistemas tiveram um aumento de solubilidade. Com a adição de água ao sistema, a solubilidade de óleo e biodiesel na fase etanol diminuiu.

A partir dos dados obtidos, o biodiesel pode ser considerado um bom agente solubilizante de sistemas envolvendo óleo + etanol. Numa abordagem à transesterificação homogênea de óleos, a presença de biodiesel é capaz de aumentar contato entre os reagentes. Os dados experimentais obtidos neste trabalho podem ser úteis para a compreensão do sistema de reação da produção de biodiesel, além de processos que envolvam a extração e transformação de óleos.

\section{Agradecimentos}

Os autores agradecem a CAPES, CNPq, PRH24, Funpar e Fundação Araucária-Paraná pelo auxílio financeiro e bolsa concedida.

\section{REFERÊNCIAS}

AOCS, Official Methods and Recommended Practices of the American Oil Chemists' Society, $5^{\text {a }}$ ed., Champaign: AOCS Press, 2001.

ATADASHI, I. M.; AROUA, M. K.; ABDUL AZIZ A. R.; SULAIMAN, N. M. N. The effects of water on biodiesel production and refining technologies: A review. Ren. Sust. Energy Rev., v. 16(5), p. 3456-3470, 2012.

DA SILVA, D. I. S.; MAFRA, M. R.; DA SILVA, F. R.; NDIAYE, P. M.; RAMOS, L. P.; CARDOZO FILHO, L.; CORAZZA, M. L. Liquid-liquid and vapor-liquid equilibrium data for biodiesel reaction-separation systems. Fuel, v. 108 p. 269-276, 2013.

DARNOKO, D.; CHERYAN, M.; PERKINS, E. G. Analysis of vegetable oil transesterification products by gel permeation chromatography. J. Liq. Chromatogr. Related Technol., v. 23(15), p. 2327-2335, 2000.

KANDA, L. R.; VOLL, F. A. P.; CORAZZA, M. L. LLE for the systems ethyl palmitate (palmitic acid)(1) + ethanol(2) + glycerol (water)(3). Fluid Phase Equilib., v. 354, p. 147-155, 2013.

MAZUTTI, M. A.; VOLL, F. A. P.; CARDOZO-FILHO, L.; CORAZZA, M. L.; LANZA, M.; PRIAMO, W. L.; OLIVEIRA, J. V. Thermophysical properties of biodiesel and related systems: (Liquid+liquid) equilibrium data for soybean biodiesel. J. Chem. Thermodyn., v. 58, p. 83-94, 2013.

OTHMER, D. F.; TOBIAS, P. E. Tie-line correlation. Ind. Eng. Chem. v. 34, p. 693-696, 1942.

SCHOENFELDER, W. Determination of monoglycerides, diglycerides, triglycerides and glycerol in fats by means of gel permeation chromatography [C-VI 5b(02)]. Eur. J. Lipid Sci. Technol., v. 105(1) p. 45-48, 2003.

VELEZ, A.; SOTO, G.; HEGEL, P.; MABE, G.; PEREDA, S. Continuous production of fatty acid ethyl esters from sunflower oil using supercritical ethanol. Fuel, v. 97, p. 703-709, 2012. 